\title{
Movimiento estudiantil y heteronormatividad: divagaciones teóricas sobre la revuelta del 2011 desde los estudios queer.
}

Student movement and heteronormativity: theoretical wanderings about the 2011's revolt from the queer studies.

Sergio Fiedler*

\section{Resumen}

La revuelta estudiantil que se desató en Chile durante el 2011 sacudió el orden políticosimbólico bajo cuyos parámetros culturales la economía de mercado se constituyó en la instancia hegemónica de regulación de las relaciones sociales. Siguiendo los aportes conceptuales hechos a los estudios queer por el trabajo filosófico de Gilles Deleuze y Felix Guattari, el siguiente ensayo intenta reflexionar teóricamente acerca de los espacios colectivos de autonomía y afectividad cotidiana asociados a esta revuelta que pusieron en tela de juicio el régimen de heterosexualidad obligatoria.

Palabras clave: movimiento estudiantil - queer - acontecimiento - cuerpo - afectividad.

\begin{abstract}
The student revolt that erupted in Chile during 2011 challanged the political and symbolic order under whose cultural parameters the market economy became the hegemonic basis for the regulations of social relations. Following the conceptual contributions to queer studies made by Gilles Deleuze and Felix Guattari's philosophical work, this essay attempts to theoretically reflect about the collective spaces of everyday autonomy and affectivity associated to the revolt that challenged the compulsory heterosexuality regime.
\end{abstract}

Key words: student movement - queer - event - body - affectivity.

Fecha de recepción: 20 de septiembre 2015

Fecha de aprobación: 04 de abril 2017 * Doctor en Sociología (Ph.D. UNSW, Australia), académico Departamento de Sociología, Universidad de
Playa Ancha. 


\section{Introducción}

Entre mayo y noviembre del año 2011 se desató en el país una revuelta estudiantil que sacudió el orden político-simbólico bajo cuyos parámetros culturales la economía de mercado se había constituido como instancia hegemónica de regulación de las relaciones sociales, sobre todo en el ámbito de la educación. Como una suerte de bing-bang político que nadie esperaba, las movilizaciones estudiantiles del 2011 desdibujaron y redefinieron radicalmente los contornos del espacio político-simbólico, provocando el sorpresivo desplome de los supuestos políticos y económicos sobre los que había descansado nuestra insípida democracia, marcando el cierre definitivo del periodo político que se había iniciado con el fin de la dictadura en 1989 (Mayol, 2012). Otro ciclo e imaginario político parecía abrirse, uno donde el mercado ya no era considerado una entelequia sacrosanta y el pensar la transformación radical del orden establecido dejaba de constituir una locura en la mente de unos pocos activistas de izquierda. No estábamos por lo tanto ante la emergencia de un mero descontento puntal hacia políticas educativas de corte neoliberal sino ante una ruptura profunda del orden político y cultural del país que no ocurría desde el estallido social contra la dictadura en los años 80s, constituyéndose en un acontecimiento colectivo que -como argumentaré más adelanteexcedió el ámbito relacionado con lo estrictamente educacional.

Me interesa abordar política y culturalmente esta revuelta estudiantil desde el punto de vista de lo "no-dicho" y de lo virtual (Richard, 2013: 216). En otras palabras, no busco describir sus causas y propiedades atendiendo simplemente a la realidad tal como se manifiesta sino articular una intervención teórico-política que permita hacer un tanteo de las tendencias micropolíticas implícitas, y a menudo imperceptibles, que hicieron el evento posible y que dieron lugar a modos de existencia que aún no han sido debidamente estudiados por las Humanidades y las Ciencias Sociales. Si bien una revisión crítica acabada de las investigaciones acerca del movimiento estudiantil del 2011 corresponde a un ejercicio que está más allá de los propósitos de este artículo, la discusión sobre las hipótesis acerca del tema desarrolladas por Bellei, Cabalin y Orellana (2014) demuestra el poco interés por parte de la gran mayoría de los analistas hacia estas tendencias. Sin desmerecer la importancia de esos enfoques, desde el punto de vista epistemológico el argumento de este ensayo apunta en una dirección muy diferente. Siguiendo la propuesta de los estudios queer y su crítica a la heteronomatividad con sus códigos binarios del género, el propósito de este artículo es hacer una lectura tentativa y exploratoria que primeramente aborde al movimiento estudiantil del 2011 desde un ángulo micropolítico y, en segundo lugar, proporcione un bosquejo teórico inicial de los modos múltiples de devenir cotidiano que lo caracterizaron en términos afectivos y sexuales, y bajo cuya lógica de acción se delineó una nueva política de la disidencia sexual 
desestabilizando el relato del régimen de hetorosexualidad obligatoria que ordena al mundo social (Halberstam, 2003)

Como campo de investigación crítica de la sexualidad y el género, los estudios queer emergen en los países de habla inglesa durante la década de los noventa en estrecha relación con el trabajo de intelectuales feministas como Judith Butler, Teresa de Lauretis y Eve Kosofsky Sedgwick, como también de una nueva generación de académicos y activistas homosexuales entre quienes se destacan Michael Warner y David Halperin (Jagose, 1998). No se debe soslayar, sin embargo, que parte del proyecto teórico de estos autores/as ha apuntado a problematizar las construcciones discursivas esencializadas de la identidad sexual y de género a partir de la crítica al sujeto de la modernidad propuesta por el posestructralismo francés asociado a Lacan, Foucault, Derrida, Delueze y Guattari.

Siguiendo por lo tanto una genealogía bajo la que se sedimentan las influencias intelectuales francesas y anglo-sajonas, los estudios queer constituyen un discurso acerca de la sexualidad que, al estar en abierto desacato a la normalización y la categorización de los cuerpos sexuados, no versa exclusivamente acerca de las experiencias gay o lésbicas como expresiones fijas de identidad u orientación sexual (Sáez, 2004). Atienden más bien a la multidimensionalidad y fluidez del cuerpo, buscando aprehender el fenómeno de la sexualidad reconociendo sus excentricidades e intensidades a través de manifestaciones de deseo que exceden las representaciones identitarias meramente heterosexuales $u$ homosexuales (lasenza, 2010). Los estudios queer están implicados en el ejercicio político e intelectual de desnaturalizar las categorías de la identidad sexual sosteniendo que éstas son cultural e históricamente específicas, de manera que la heterosexualidad como matriz reguladora implícita en el orden económico y estatal no corresponde a un precepto fijo y universal, sino a un proceso cultural y corporal siempre sujeto a la posibilidad de su desmantelamiento (Duggan, 1994).

En vista de la relevancia político-teórica que la obra colaborativa de Deleuze y Guattari ha tenido en los estudios queer en la última década (Nigianni y Storr, 2009), un nuevo bagaje de conceptos se ha incorporado a la reflexión crítica sobre la sexualidad y el género, entre los que se incluyen las nociones de agenciamiento, acontecimientos, cuerpo y afectos, y la crítica al orden social familista expuesta en el texto Anti-Edipo. Siguiendo la trayectoria teórica delineada por estos términos, el presente texto se estructura en tres partes. La primera examina la relevancia político-cultural del movimiento estudiantil del 2011 en términos de los conceptos de agenciamiento y acontecimiento, considerando la reverberación micropolítica del movimiento a través del campo de lo simbólico y social.

Siguiendo los aportes teóricos de los estudios queer, esta sección también explora el concepto de heteronormatividad como expediente constitutivo del capitalismo y el ordenamiento político administrativo de la nación. La segunda parte aborda la centralidad del cuerpo y sus afectos en la constitución del movimiento estudiantil. Por último, el 
ensayo examina la significancia de las ocupaciones o tomas de establecimientos educacionales de enseñanza media durante la movilización del 2011, cuyos modos de intimidad y relacionalidad afectiva socavaron las bases teleológicas, heterosexuales y edípicas que sostienen a la familia conyugal.

\section{La rebelión estudiantil como acontecimiento}

Las primeras movilizaciones estudiantiles de importancia tuvieron lugar en mayo del 2011. Si bien fueron de gran masividad, tendieron a desarrollarse por los cauces de manifestación callejera que había caracterizado al activismo estudiantil universitario desde el fin de la dictadura. Las demandas tampoco eran nada nuevo: aumento del financiamiento a la educación pública, acelerar el proceso de entrega de becas y el pase escolar. No obstante, ante la inconformidad con la respuesta dada por el gobierno de centro-derecha encabezado por Sebastián Piñera, los estudiantes radicalizaron sus movilizaciones y marchas. El paro nacional universitario del 1 o de junio paraliza las actividades de las universidades chilenas y desata una ola de ocupaciones de edificios universitarios, movimientos al que se suman los estudiantes secundarios con paros y tomas indefinidas de establecimientos educacionales a lo largo del país. Se estiman que para el 10 de julio había más de 150 liceos en toma sólo en el Área Metropolitana (Rojas y Méndez, 2014). Para esa fecha las demandas iníciales habían dado paso al llamado por una educación gratuita y de calidad, aunando al movimiento estudiantil con otros sectores de la sociedad civil que comenzaron a participar activamente en las movilizaciones estudiantiles y entre los que se contaban organizaciones sindicales y profesionales como también de padres y apoderados. Ya no estábamos simplemente ante una marcha estudiantil más, sino ante una erupción social que interpelaba a la sociedad en su conjunto y mantenía una cierta relación de sincronía política con otros movimientos sociales que emergían alrededor del mundo durante el mismo periodo, como fue el caso de Los Indignados en España, el movimiento Occupy en Norteamérica y la Primavera árabe.

La revuelta estudiantil del 2011 constituyó un verdadero acontecimiento. De acuerdo a Deleuze (1990), un acontecimiento se debe entender como al instante singular en que algo nuevo ocurre, cuando de manera intempestiva una partícula salta de la estructuralidad de su órbita y desterritorializa los límites de lo que conformaba su contexto, produciendo una época histórica donde surgen agenciamientos y enunciados colectivos de nuevo tipo (Deleuze, 2010). Dice relación con un acaecimiento de intensidades que se extiende transversalmente por los cuerpos, como el agua que llega al punto de ebullición que la transforma en vapor que invade el espacio. No les ocurre a las cosas o a las personas toda vez que ocurre a través de ellas (Adkins, 2012). Hablamos de un momento de fractura o punto de fuga en una formación social que, condicionado por la historia y la situación social de la que surge, no está completamente determinado por éstas, desbordándolas radicalmente y creando un terreno donde emerge una relación 
entre cuerpos y fuerzas políticas totalmente innovadora e irreversible (Deleuze y Guattari, 1987). El acontecimiento es el momento de interrupción del régimen ordinario de la política y la producción del conocimiento que tiene características eminentemente constituyentes. Y que en caso del movimiento estudiantil emana de su capacidad de autoconstituirse y auto-organizarse cooperativamente como multitud, generando a partir de sus actos de rebelión y éxodo, un agenciamiento de enunciación colectiva que prefigura nuevas relaciones sociales y formas de vida; tiene como soporte material el encuentro afectivo y creativo entre cuerpos que se reúnen y potencian mutuamente, produciendo en torno a la asamblea, la consigna, la marcha, la toma o la barricada, nuevos regímenes de expresión lingüística y no-lingüística (Hardt y Negri, 2000).

El acontecimiento es un ubicuo cambio de intensidades: involucra la interconexión de todos los acontecimientos individuales de manera que cada punto singular donde algo nuevo ocurre está conectado a otro punto singular donde también sobreviene algo nuevo, resonando en conjunto a pesar de sus disyunciones y ramificaciones, produciendo una multiplicidad de la multiplicidad que da forma unívoca a un mismo acontecimiento (Deleuze, 1990). Como acontecimiento, las movilizaciones estudiantiles, con su variado y corporalmente expresivo repertorio de acciones callejeras, operan como fuerza de enunciación que transforma y subvierte los equilibrios hegemónicos del poder, poniendo en evidencia el carácter abierto, inestable e indecidible del campo social. La protesta estudiantil sería un acontecimiento no porque ocurra sino porque asombra, porque existe a través de la performatividad de su propia sorpresa (Nancy, 2000). Estar ante el acontecimiento es estar ante un acto performativo (Butler, 1997): la producción de un excedente o plusvalor enunciativo que impulsa un cambio radical en las reglas del espacio simbólico, modificando el horizonte de lo que es considerado posible y deseable, produciendo un nuevo "reparto de lo sensible" (Rancière, 2009), dejando entrever las potencialidades subyacentes a los cuerpos normados y regimentados por la reproducción social.

Como agenciamientos colectivos, las marchas estudiantiles durante este periodo proporcionan un ejemplo del carácter de acontecimiento que tiene la revuelta del 2011 respecto a formas de movilizaciones social existentes en Chile en las décadas de los 70 s y 80 s. En términos de su expresividad estética, espontaneidad corporal y multiplicidad carnavalesca, las marchas del 2011 representan un quiebre con respecto a formas de movilización social más tradicionales que se han caracterizado por la influencia hegemonizadora de las vanguardias políticas. Si bien el liderazgo de dirigentes de las Juventudes Comunistas como de la Izquierda Autónoma tuvo una presencia mediática significativa, las movilizaciones callejeras ocurrieron sin el pauteo uniforme de una dirección política. De acuerdo a Urzúa Martínez (2015), lo que predomina en las marchas es una multiplicidad de performances corporales disputando el espacio público y transformando -al menos transitoriamente- sectores neurálgicos de la ciudad de Santiago en verdaderas zonas liberadas como forma de interpelación hacia las autoridades 
políticas. Los manifestantes hacen de la marcha un carnaval de cánticos, danzas, alegorías, maquetas, pancartas con mensajes individuales y colectivos, en un gasto festivo y espontaneo de energías corporales que interrumpe la normalidad de la ciudad neoliberal.

El movimiento estudiantil del 2011 nunca fue homogéneo. El poder de su acaecimiento radica precisamente en la capacidad que tiene su multiplicidad de nodos y relaciones para expandirse a través del campo de lo social. Constituye una propagación de singularidades agenciadas descentralizadamente, de devenires moleculares/minoritarios, cada uno de las cuales está investido con una subjetividad y un modo propio de enunciar y comprender la significancia del movimiento en su conjunto (Deleuze y Guattari, 1987).

Estas singularidades rebasan y subvierten los procesos de representación política, produciendo una red de relaciones por medio de las cuales, las organizaciones estudiantiles oficiales como la FECH, CONFECH, CONES y ACES se transforman en nodos de un agenciamiento más amplio, múltiple y complejo, cuya intensidad autotransformadora y constituyente no se ajustan con facilidad al imperialismo de una dirección centralizada y única. Si el movimiento estudiantil constituye un acontecimiento de envergadura en términos de la modificación de un estado de cosas establecido, es precisamente por el peso de la revuelta cotidiana asociado con la proliferación y la intensidad de los devenires molecular/minoritarios que emergen de la interacción afectiva entre los cuerpos y de la experimentación colectiva que va componiendo a diario el movimiento. El movimiento estudiantil se expande transformando el contexto de relaciones de fuerzas, invistiendo otros movimientos con mayores grados de potencia e intensidad: cuerpos subalternos se movilizan desde locaciones marginadas y remotas, estremecen el centro de la soberanía a partir de luchas por el medio ambiente, por la descentralización administrativa, por la calidad de vida, y entre los cuales se incluyen devenires relacionados con procesos de singularización de la sexualidad y el género (Guattari, 2013). Los feminismos, las homosexualidades, los lesbianismos, las transexualidades, la disidencia sexual, conforman trayectos moleculares que atraviesan el movimiento estudiantil en su conjunto. No es un dato menor que durante el transcurso de la revuelta estudiantil se suscita cada vez más apoyo ciudadano para con la lucha por los derechos sexuales y reproductivos, situación que genera una mayor visibilidad y empoderamiento para las organizaciones LGTB y el activismo feminista, además de dar forma a un nuevo activismo de la disidencia sexual que -como lo veremos más adelantecoalesce en los mismos espacios con el movimiento estudiantil.

La revuelta del 2011 por lo tanto no puede ser pensada eludiendo el tema de la sexualidad. La crisis institucional generada por el movimiento estudiantil deja en evidencia que la educación, la heteronormatividad y el capitalismo están estrechamente conectados entre sí por un complejo modo de producción e inscripción de cuerpos que hace necesaria la articulación de discursos y estrategias de resistencia comunes, como 
forma de responder globalmente ante problemas de opresión que no parecen a primera vista conectados entre sí. La heteronormatividad no es un régimen de regulación de los cuerpos sexuados que sea autónomo de la estructuración del poder asociado al Estado, la etnicidad y las clases sociales. La heteronormatividad compone una red de relaciones de poder marcadas por su dispersión, sobrecodificando e invistiendo el campo de lo social en su conjunto (Córdoba, 2005). De acuerdo a los estudios queer, la definición binaria entre una heterosexualidad dominante y mayoritaria por un lado, y una homosexualidad subordinada y minoritaria por el otro, constituye parte fundamental del marco teórico de toda la cultura moderna, occidental, cristiana y capitalista. Cada institución económica y política de la modernidad es una institución sexuada, esculpida por las visiones hegemónicas y binarias del género. La masculinidad y la feminidad implican representaciones del cuerpo trabajando al interior de los procesos institucionales como un par complementario definido exclusivamente en términos del deseo heterosexual que a su vez se convierte en el único deseo sexual legítimo y natural. La relación dismórfica y políticamente asimétrica entre los sexos depende de los fines reproductivos impuestos por la obligatoriedad, obviamente patriarcal, de la heterosexualidad (Rich, 1996; Wittig, 2010). Como señala Judith Butler (2007: 81), la heterosexualidad se debe entender como un régimen de poder obligatorio que naturaliza y regula el género bajo un orden de relaciones binarias en que el término masculino se diferencia del femenino, y esa distinción se alcanza por medio de "la práctica del deseo heterosexual. El hecho de establecer una distinción entre los dos momentos opuesto de la relación binaria redunda en consolidación de cada término y la respectiva coherencia interna de sexo, género y deseo".

Tanto las instituciones del Estado como del mercado tienen como uno de sus puntos de partida la heterosexualidad como matriz de inteligibilidad para todos sus discursos y operaciones prácticas, dentro de la cual el matrimonio heterosexual, monógamo y dirigido hacia la reproducción es considerado la base naturalizada y única sobre la cual descansa el orden social. A partir de dicho supuesto patriarcal y familista, se diseñan las políticas públicas, se organiza el mercado laboral, se reparte la ciudadanía, se asignan los derechos y deberes y se orientan las campañas de marketing. Toda práctica sexual en que el deseo no se ajuste a las expectativas de conducta del género binario se convierte en objeto de rechazo, siendo castigada con la invisibilidad política y cultural por parte de estos procesos institucionales. Dentro de ese entramado de relaciones de poder, el sistema de educación es uno de los pilares más importantes de la construcción heteronormada de los cuerpos. Cuando se habla de la educación en Chile como un negocio lucrativo, se debe incluir en este lucro al proceso libidinal de instrucción corporal que insiste que la única sexualidad legítima es la heterosexual, reproductiva y monógama, donde ser fiel al placer sexual de los cuerpos es considerado un desvío de las labores productivas y reproductivas que las lógicas del mercado demandan. Es importante señalar, sin embargo, que éste no corresponde a un régimen político de sexualidad cerrado, estable y coherente como si fuese una totalidad fija dentro de la cual no pudiese 
ocurrir ninguna resistencia o subversión corporal. A pesar que la heterosexualidad obligatoria permea todo el cuerpo social, no se puede reducir a una norma subyacente que regula las conductas de un modo unilateral y definitivo. Particularmente en el campo del sistema educativo, las relaciones de poder - como sostiene Foucault (2012)- son siempre dinámicas y reversibles, moduladas por resistencias, deterritorializaciones e iteraciones en el sentido de su significación, lo que hace de la norma heterosexual un proceso de producción y regulación del cuerpo cuyas operaciones de poder e identidad son siempre parciales y temporales, abiertas a cambios y rupturas, que se modifica de acuerdo al contexto en que se encuentren citadas, abriéndose por tanto a la posibilidad del "acontecimiento impropio" (Butler, 2008: 318).

De acuerdo a los estudios queer, toda identidad sexual es siempre relacional, dinámica e inestable. La aceptación del mandato heterosexual por parte del cuerpo no ocurre sin prescindir de la homosexualidad como referente simbólico-lingüístico. Dentro del espacio discursivo del régimen de sexualidad contemporáneo, la heterosexualidad y la homosexualidad están estrechamente conectadas entre sí por los mismos mecanismos de poder, sin que dicha relación -sin embargo- sea igualitaria: el término "heterosexual" siempre retiene el lugar de un cuerpo primario, dominante y estable, mientras el término "homosexual" ocupa la posición de un cuerpo subordinado, desordenado y abyecto. No obstante, el término "homosexual" juega la función imaginaria de un otro que le indica al "heterosexual" todo lo que no es, no puede y no debe ser. El homosexual es el medio que tiene el heterosexual para constituir y delimitar su propia identidad, el límite interior que le permite estar al tanto que existen otras conductas y deseos que lo pueden mancillar y está obligado a repudiar de manera permanente en el esfuerzo -a menudo fallido- de mantener una identidad sexual inalterable. La homosexualidad es producida como el otro imaginario donde el heterosexual proyecta sus dudas acerca de su propia sexualidad, el reflejo especular por medio del cual este último reafirma simbólicamente su sentido de superioridad y elude reconocer la homosexualidad misma como el verdadero punto de apoyo fundacional de su identidad (Halperin, 1995).

Al constituirse simultáneamente en amenaza y soporte de la heterosexualidad, la homosexualidad se convierte en el suplemento que impide que la heterosexualidad se transforme en una totalidad auto-suficiente y completamente suturada (Derrida, 1973), indicando la imperecedera presencia de una falta -en términos lacanianos- o un exceso en términos deleuzianos- en la estructura de la heterosexualidad que inevitablemente genera su inestabilidad. Según David Córdoba (2005: 50), al "establecer y prohibir un afuera, al delimitarlo y darle existencia, la heterosexualidad subvierte en este mismo mecanismo sus propias pretensiones de ser natural y necesaria, ya que lo que está prohibido no es imposible y precisamente por eso es necesario prohibirlo".

La pretensión esencialista de construir identidades sexuales fijas y coherentes, construidas sobre la oposición binaria entre lo femenino y lo masculino, o entre lo 
heterosexual y lo homosexual, estaría, desde este punto de vista, siempre destinada al fracaso ya que el retorno involuntario de lo reprimido siempre pone en evidencia el carácter frágil e ineficaz de los mandatos que producen la identidad heterosexual (Butler, 2007).

La heterosexualidad es un ideal normativo ante el cual los cuerpos buscan obsesivamente ajustarse, pero sin tener jamás completo éxito, abriendo al interior de las prácticas, deseos y discursos que estos propios cuerpos producen, notables fisuras e incoherencias en relación a este ideal normativo, posibilitando la creación de pliegues sexuales alternativos y heterotópicos diseminados en varias instancias de lo social, incluyendo el propio sistema de educación. Por lo tanto, las rebeliones o resistencias a la heteronormatividad patriarcal no deben buscarse exclusivamente entre las "minorías" gay o lésbicas o la vanguardia de la disidencia sexual. Los puntos posibles y potenciales para resistir o escapar a la heteronormatividad son múltiples, diseminados por todo un campo social en sí mismo marcado por las huellas de la heterosexualidad, y que no necesariamente se definen a sí mismos como abierta o intencionadamente sexuales en sus objetivos políticos. Las nuevas experiencias de intimidad y afecto aquí no tienen su origen ni toman forma, en consecuencia, a partir de un sujeto revolucionario o sexo disidente homogéneo y míticamente puro.

\section{Cuerpos y afectos}

¿Es el movimiento estudiantil entonces eminentemente heterosexual? Sin duda alguna que la gran mayoría de los participantes en el movimiento se definirían a sí mismos estadísticamente- como heterosexuales. Producto de su mayor sensibilidad hacia los devenires molecular/minoritarios asociados con la sexualidad, los estudios queer en cambio no darían una respuesta afirmativa ni negativa, más bien pondrían a la pregunta misma en permanente suspenso, problematizando los supuestos normativos que la sostienen en relación con la categorización del deseo sexual.

Si el movimiento estudiantil del 2011 encuentra un lugar de resonancia común con los estudios queer, no es porque se refiera directamente a heterosexualidad o la homosexualidad, sino porque implica devenires eróticos y afectivos basados en la diferenciación de cuerpos que construyen nuevos modos de existir o hábitos de vivir que transgreden el régimen de lo normal (Warner, 1993) basado en la oposición binaria entre homosexual y heterosexual. Claramente el movimiento estudiantil no articula movilizaciones ni discursos en torno a estos temas, sin embargo, las desobediencias y las interacciones corporales que lo constituyen como movimiento tienen connotaciones políticas y culturales inevitablemente sexuadas que, sin proponérselo conscientemente, exceden y subvierten aquellos discursos oficiales que borran la significancia política de los cuerpos sexuados. 
Ya no es posible considerar el cuerpo simplemente como el efecto o materialización de un discurso o régimen regulatorio de la sexualidad. El cuerpo no es una página en blanco o una materia estática y pasiva sobre la cual se estampan ciertas inscripciones culturales y de poder. El cuerpo es parte de un movimiento que le es propio, cuyos afectos producen conexiones múltiples y energías constituyentes que transforman, fracturan y desterritorializan el espacio discursivo que lo hacen inteligible. La multiplicidad y plasticidad de los cuerpos estudiantiles han producido un acontecimiento que fractura los equilibrios hegemónicos en el ámbito de lo político y lo sexual. Se hace necesario considerar la importancia que tiene la materialidad del cuerpo y sus afectos como condición para la aparición de un mundo distinto, poniendo el énfasis en las percepciones, sensaciones, las intensidades y todos los movimientos corpóreos que excedan el imperio performático del significante lingüístico. Hablar de movimiento social es hacer referencia también a la afectividad, al cuerpo como agenciamiento, donde materialidad y discurso son co-constitutivos en la producción del cuerpo sexuado.

El movimiento estudiantil indica precisamente que la potencia de un movimiento social y de una acción política no radica simple o necesariamente en un programa o las interpelaciones discursivas. Las prácticas del cuerpo no pueden ser explicadas simplemente a partir de categorías cognitivas o discursivas. La conciencia intencionada no está siempre al tanto del cuerpo que la carga, siempre es de alguna manera arrastrada por el cuerpo sin dejar de ser nunca una de sus partes. Los movimientos corporales expresan más que las palabras, toman el lugar del habla, convirtiendo al mismo cuerpo en terreno desde donde emanan los signos y el pensamiento (Jackson, 2011).

La conciencia y el lenguaje son simplemente partes disminuidas del cuerpo y sus afectos, nunca lo abarcan, porque el cuerpo es en verdad inabarcable en sus potencialidades. Esta relación de discontinuidad o desajuste entre el cuerpo, su conciencia y sus discursos da un primer indicio de su multiplicidad, de aquella subjetividad escindida que nunca deja de estar lo suficientemente tematizada por la Filosofía o las Ciencias Sociales contemporáneas. No podemos tratar al cuerpo como un vehículo de las intenciones o como un efecto del discurso o de las normas sin perder de vista la capacidad que tiene el cuerpo para afectar y ser afectado de múltiples modos y cómo se incrementa o reduce su poder de actuar a partir del encuentro con otros cuerpos (Deleuze, 1988).

Siempre hay en todo cuerpo una parte incompleta, inacabada, algo que queda por experimentar, un potencial que queda por descubrir, algo profundamente intenso que queda por desear. El cuerpo es un territorio abierto. No está solo, no puede existir sin otros cuerpos. El cuerpo actualiza su existencia expresando sentidos y emociones que sólo pueden constituirse con y por medio de otros cuerpos que son diferentes del mío. Por lo tanto, cualquier modalidad de pertenencia y vínculo no depende de una red de valores y creencias compartidas inamovible, sino de la dinámica de diferencias que existen entre los cuerpos, que hacen de la cultura una dimensión flexible y abierta a 
devenires y mutaciones. La intercorporalidad que se produce en "la carne", para usar el concepto de Merleau-Ponty (1970: 166-169), es el elemento del ser donde el sentido y el afecto son expresados, transformándose en la textura y principio del entrelazamiento donde mi cuerpo está sujeto al mundo por medio del cuerpo de los otros.

En este entrelazamiento corporal, lo visible, lo tocable y lo audible no están completamente separados, pero tampoco completamente unidos, ya que "la carne" es capaz de percibir y sentir sólo por medio de la divergencia o la separación. Al ser tocado, por ejemplo, mi cuerpo ya habita y es habitado por otro cuerpo en la producción de sentido y afecto, provocando discordancias expresivas, diferencias entre tocar y ser tocado. Esta es la paradoja de la distancia en proximidad que constituye lo social, que construye un movimiento, que mueve al deseo. La relación de diferencia que existe entonces entre los cuerpos que tocan y son tocados, ven y son vistos, escuchan y son escuchados, no constituye alienación o extrañamiento, sino la condición de la comunicación. La expresión social del cuerpo por lo tanto involucra el simultáneo movimiento de separación y comunión en el proceso de constituir y modificar los modos de pertenencia, donde el sentido compartido es el resultado de la relación que mantengo con cuerpos que nunca son similares al mío. La fuerza de un movimiento social se pone de manifiesto precisamente con el proceso de desorientación afectiva que genera el ser tocado, mirado o escuchado por un extraño, pero que a la vez se mantiene abierto a esta alteridad, paradójicamente, como condición ontológica para la construcción y mantención de la comunidad (Diprose, 2005).

\section{Edipo y la toma como espacio y temporalidad queer}

El movimiento de tomas de colegios se desencadenó entre junio y noviembre del 2011, teniendo como poderoso antecedente las ocupaciones estudiantiles, más acotadas y menos radicales, ocurridas durante la "Revolución Pingüina" del 2006. No es la primera vez que el cuerpo militante de la multitud ocupa un espacio urbano para transformarlo en territorio y subjetividad política. Aunque el Estado la impugne como un atentado violento y anti-democrático al orden ciudadano de la democracia liberal, en la larga historia del poder constituyente en Chile la toma ha sido esgrimida por la multitud como modalidad de acción directa para enfrentar problemas políticos y sociales urgentes que los gobiernos de turno no tienen la voluntad de resolver como la vivienda, la tierra, la producción y ahora la educación. Desde las ocupaciones ilegales de sitios por los "sin casa" que daría lugar al movimiento de pobladores, la toma ha sido una herramienta habitual de autogestión utilizada por estudiantes universitarios, trabajadores y campesinos para recobrar espacio y tiempo de vida, incluyendo a sus propios cuerpos, de las reclusiones disciplinarias asociadas a los diferentes modelos institucionales de desarrollo social (Salazar, 2012). El movimiento secundario del 2011, sin embargo, le imprime a esta ilustre tradición y método de lucha un sello micropolítico propio, que no sólo lo revive y lo potencia, sino que lo convierte en una instancia radical de revolución cotidiana. 
Las tomas de colegios fueron una expresión autónoma de organización social y poder constituyente (Negri, 1999) que se distinguieron de otros movimientos sociales por el hecho que sus protagonistas fueron jóvenes estudiantes secundarios, muchos de los cuales aún no habían alcanzado la mayoría de edad. Mientras que la infancia ha permanecido invisible y sin ciudadanía en los textos de ciencias políticas y movimientos sociales, siendo relegada a un espacio conceptual que considera su rebelión como apolítica o pre-política; las tomas realizadas por los estudiantes secundarios redefinen el lugar político de lo que ha sido considerado oficialmente como "infancia" y "adolescencia", desestabilizando en sus fundamentos ontológicos el carácter marcadamente adultocéntrico que, según Olga Grau (2004, 2006), han tenido las concepciones hegemónicas de niñez y juventud en Chile. Aún más, dentro de la dinámica marcadamente biopolítica que tiene la toma en términos de autogestión de la vida cotidiana, los estudiantes secundarios consuman una fracturación e interrupción del ciclo de reproducción y normalización disciplinaria asociada con las jerarquías y mandatos familiares.

Como forma local de poder constituyente, toda toma trabaja colectivamente sobre la reconstrucción autónoma y horizontal del tiempo y el espacio, pero que en el caso del movimiento secundario deviene en una multitud en éxodo, cuya radicalidad efectiva implica la acción directa de cuerpos "infanto-juveniles" que dejan en los hechos de adherir a la "protección" de la familia nuclear y su repertorio de estatutos patriarcales, edípicos y heteronormativos.

La matriz heterosexual y las normas del género implican una construcción narrativa en torno a lo social que es profundamente teleológica, lineal y evolutiva en la manera de categorizar y marcar los cuerpos. Como hemos señalado, la heteronormatividad naturaliza la relación binaria y de subordinación patriarcal entre el hombre y la mujer como un bien universal y moral ante el resto de la sociedad, señalando al matrimonio, la reproducción de los hijos, el trabajo asalariado y la acumulación de bienes como el corolario directo y obligatorio de dicha relación de subordinación. Sin duda que éste es un orden social que tiene puntos de fuga, filtraciones que aparecen por todas partes, como queda en evidencia cuando se aprecia la cifra creciente de hijos que nacen fuera del matrimonio, la tasa de divorcio y las pérdidas de la propiedad familiar producto de las recurrentes crisis económicas. Podríamos decir que la heteronormatividad como logro social efectivo es el privilegio de una minoría, lo que no significa sin embargo que haya perdido la eficacia simbólica y por lo tanto hegemónica sobre gran parte de la población.

La familia nuclear, patriarcal y edípica continúa siendo la fantasía institucional y el emprendimiento con mayor valoración económica, social y política bajo el orden del capitalismo neoliberal en Chile y cuya pertenencia es una condición primaria para ser sujeto de credibilidad y crédito para el mercado. 
Como lo señala Olga Grau (1997), el imaginario familista prevalece con fuerza en la sociedad chilena. La familia y los valores patriarcales continúan existiendo, aunque el patriarca ya no esté o se encuentre severamente debilitado en sus atribuciones, situación que se ajusta perfectamente al postulado lacaniano que concibe a la Ley del Padre como el precepto simbólico que precisamente viene a llenar el vacío que el padre real o biológico ha dejado con su ausencia (Lacan, 2001).

De acuerdo a Araujo y Martuccelli (2012: 180-181), puede que hoy en día exista una mayor diversidad de unidades domésticas que no concuerdan con el modelo de familia heterosexual biparental con hijos basada en el matrimonio, no obstante esta última continúa siendo una matriz hegemónica que ordena y regula las relaciones entre los individuos, "estableciendo de manera estricta las funciones que cumplen unos respecto a otros, especialmente en la relaciones entre padres e hijos; definiendo rigurosas obligaciones de sociabilidad; y prescribiendo normas sobre los compromisos de ayuda reciproca". Como queda claro con las demandas asimilacionistas por el matrimonio igualitario de parte de organizaciones como el MOVILH, la Fundación Iguales, MUMS y Acción Gay, la Ley del Padre continúa ejerciendo un peso simbólico-lingüístico en la medida que los sujetos, independiente de su orientación sexual y género, siguen definiéndose a sí mismos en torno a los mandatos y expectativas del progreso heterosexual expresados por el matrimonio monógamo, la reproducción y la herencia de la propiedad.

La heterosexualidad como norma tiene sus inicios filogenéticos en la triangulación edípica de la líbido infantil al interior de la familia nuclear desde donde se proyecta a todo el campo de lo social, convirtiéndose en una de las doctrinas políticas oficiales del Estado y el capital (Deleuze y Guattari, 1994). El mito psicoanalítico es proverbialmente conocido. Basándose metafóricamente en la tragedia de Sófocles Edipo Rey, donde Edipo sin saberlo asesina a su padre y desposa a su madre, Freud conceptualiza el Complejo de Edipo para designar simbólicamente una triangulación ambivalente de deseos amorosos y hostiles que el niño y la niña experimentan en relación a los padres, y cuyas diferentes modalidades de planteamiento y resolución tienen un impacto directo en el deseo y orientación sexual (Freud, 1986). Como mecanismo de sujeción psíquica que se conjuga con la represión social, el Complejo de Edipo establece límites a las múltiples formas y conexiones que el deseo sexual pueda tomar, introduciendo a un niño o niña sexualmente polimorfo a la sexualidad binaria entre los géneros y por ende al mandato cultural de una heterosexualidad genital obligatoria.

De acuerdo a Deleuze y Guattari (1994) su eficacia como mecanismo heteronormativo depende precisamente en hacer intervenir la función paterna como instancia prohibitiva y reguladora de la libido infantil donde, bajo la figura de la castración, el sujeto infantil e infantilizado es producido por medio de la aceptación del paradigma fálico de la Ley del 
Padre que obliga a aceptar la heterosexualidad reproductiva como única forma de erotismo posible. Asegura que los deseos del niño y la niña se mantengan debidamente triangulados dentro de la familia conyugal por medio de sentimientos de temor hacia la figura del padre y de culpa en relación a la madre, para ser luego debidamente invertidos y mercantilizados dentro de las relaciones de producción capitalistas propiamente tal.

La Ley del Padre opera como otra de las leyes del mercado. Pensemos cómo en Chile los efectos de desterritorialización que han tenido las políticas neo-liberales sobre las relaciones laborales y los lazos comunitarios de solidaridad, han creado presiones materiales y afectivas sobre la economía doméstica que han ciertamente tensionado y fracturado el lazo familiar, pero también lo han convertido en un tema de vida o muerte para aquellos que experimentan con más fuerza las demandas económicas y simbólicas que impone el mercado (Halberstam, 2007). En el marco de un modelo de desarrollo social y económico basado en la expansión de las precariedades laborales y emocionales, la familia nuclear aparece por tanto como la instancia más confiable de apoyo y protección comunitaria, instalándose en el imaginario colectivo como un espacio de apego libidinal casi en peligro de desaparecer, como si el sujeto estuviera adhiriendo al último residuo o trinchera de comunidad que quedase para enfrentar la crueldad del mercado (Tironi, 2005).

Para Deleuze y Guattari (1994), el capital extrae su propia ganancia de las relaciones privatizadas de la familia nuclear, la que se modela a su vez en torno a las funciones del modo de producción capitalista. El rol de padre, madre e hijos dentro de la familia conyugal no tienen fundamentos ontológicos autónomos, son más bien el simulacro de las imágenes creadas por los procesos de representación capitalista, donde el padre es el simulacro del capitalista, la madre el simulacro de la tierra, y los hijos el simulacro del proletariado. De la misma manera que el capital gobierna el acceso de los trabajadores a los recursos de la tierra, la función paterna coordina las diferentes relaciones de producción que el niño o la niña puede tener con su entorno. La triangulación edípica funciona como un cedazo: actúa selectivamente, admitiendo las imágenes de deseo y fantasía que puedan ser conjugados con la producción capitalista, permitiendo su integración al mundo público, mientras que las imágenes de deseos y fantasías sexuales que no obedecen a las finalidades reproductivas del capitalismo, permanecerán reprimidas al interior del espacio privado de la familia nuclear.

De acuerdo a los estudios queer, la heteronormatividad es mucho más que la naturalización de las relaciones sexuales con el sexo opuesto y la patologización de las prácticas y deseos homosexuales. La heteronormatividad también deviene en otra modalidad del lucro que el capital extrae desde los cuerpos y que, como Halberstam (2011) asevera, implica la sujeción a un disciplinamiento productivo permanente que obliga a los cuerpos a transitar desde una infancia o adolescencia desordenada y anárquica, marcada por sentimientos edípicos de temor y culpa hacia los padres, a una 
adultez ordenada y predecible, donde el éxito como el fracaso siempre dependen del emprendimiento individual y nunca se entienden como el resultado de la estructuración antagónica de los cuerpos bajo categorías raciales, de clase y género.

La matriz heterosexual se sostiene, según Halberstam, de manera conjunta con la lógica capitalista de la acumulación de logros y realizaciones morales y económicas, mientras que los cuerpos que no se ajustan a esta matriz son marcados por una historia queer o sexo-disidente asociada al fracaso, la pérdida y la imposibilidad de reproducir. "El capitalismo señala al homosexual como inauténtico e irreal, como inhábil para amar propiamente e incapaz de hacer las conexiones apropiadas entre socialidad, relacionalidad, familia, sexo, deseo y consumo" (Halberstam, 2011: 94). La heterosexualidad, por otra parte, está directamente relacionada con el deseo de progreso y de perseguir ese proceso lineal entre familia, educación y trabajo, culminando con la formación de una nueva familia nuclear, presumiendo un cuerpo que siempre se ve obligado a moverse relacional y armónicamente desde etapas inferiores a etapas superiores de desarrollo psicosocial.

Concordando con Lee Edelman (2004) quien, desde una lectura lacaniana al interior de los estudios queer, señala que es imposible concebir este futurismo reproductivo heterosexista sin la figura política y cultural de la infancia como el signo más amado y a la vez más odiado de la modernidad occidental. Edelman sostiene que, a pesar de la importancia que la heterosexualidad obligatoria le confiere a la procreación de los hijos como condición para la producción de lo social, bajo su orden normativo la niñez también constituye un obstáculo anti-social para la procreación y el tránsito exitoso hacia el futuro. El tener hijos es signo de madurez, de que se ha sorteado paradójicamente la etapa de la niñez. La infancia se convierte en una fase de la vida que, de no ser superada, se transforma en enfermedad; en una locura que, de no ser sobrellevada, nos dejará sin futuro (Berlant, 1997; Foucault, 2000). El homosexual, desde este punto de vista, es quien, aun siendo un adulto, está impedido de plena adultez ya que parte de su personalidad se quedó sin completar, estancada en una etapa de desarrollo psicosexual inferior. El deseo por el mismo sexo o las prácticas sexuales divorciadas de la procreación manifiestan una conducta infantil pre-edípica que, según el psicoanálisis tradicional, habla de una constante incapacidad por parte del homosexual de completar el proceso de reproducción tanto biológico como social, faltando a una recursividad societal que queda claramente simbolizada en los ya proverbiales comentarios homofóbicos como "se le quedó la patita atrás" y "se le quemó el arroz".

¿Pero qué ocurre cuando los niños y niñas se rebelan y son ellos mismos los que se escapan del espacio y el tiempo que se les ha asignado de manera naturalizada por el poder adultocéntrico y heteronormado? ¿Acaso no fue también el movimiento de las tomas de establecimientos de educación por parte los jóvenes estudiantes secundarios, 
una rebelión contra un modelo de desarrollo psico-sexual organizado en torno a la fantasía neoliberal y heterosexual del futuro?

Las tomas de colegios se construyen sobre modos de sociabilidad comunitarios y horizontales que distan radicalmente de las jerarquías familiares y pedagógicas que existen fueran del tiempo y el espacio de la toma. Desde esta comunidad autónoma, se comienzan a gestionar en común funciones de reproducción, educación y seguridad que tradicionalmente han sido realizadas de manera autoritaria por el Estado o la familia. En medio de la transformación del espacio del colegio que la toma involucra, muy en especial con la redefinición de las funciones de la sala de clases, se produce la emergencia de la multitud, donde cada gusto y estilo, cada cuerpo y deseo singular, tienen su lugar y tiempo de expresión y conexión propios. Como sostiene el antropólogo Oscar Aguilera (2006) en su estudio sobre la toma del Colegio Eduardo de la Barra durante el movimiento pingüino del 2006, las tomas producen una nueva modalidad de vida, una nueva manera de estar junto al otro. El gay, el punk, el hiphopero, el reggetonero flaite y el nerd, tanto las mujeres como los hombres, comparten un espacio en común, se comunican y coordinan a partir de sus diferencias, sin ser jamás sobrecodificados por un discurso único, sin diluirse o renunciar a su propia singularidad, a su propia "movida" de multitud, sacándole partida a las nuevas salas-habitaciones como enclaves para sus propias expresiones subculturales, convirtiendo las tomas en un ambiente social lo suficientemente libre como para que los estudiantes homosexuales se sientan empoderados para "salir del closet" y manifestar libremente sus preferencias sexuales $\sin$ ser discriminados por sus pares. En algunos casos, la disidencia sexual en las tomas de colegios adquiere ribetes aún más radicales, apuntando explícitamente a articular una política sexual al interior del movimiento estudiantil.

De la toma del Liceo A90 nace el colectivo A Quemar el Closet, mientras que en el Liceo Lastarria emerge el colectivo Las Putas Babilónicas. Como uno de los logros de las tomas fue la implementación de horarios protegidos que permitían a los estudiantes disponer de horas pedagógicas para realizar talleres con contenidos decididos por ellos mismos. Las Putas Babilónicas comenzaron a hacer talleres autogestionados sobre sexualidad a sala llena en el Liceo 7. Como lo señala Juana la Loca, uno de los integrantes del colectivo, en estos talleres se hablaba de educación sexual y de identidad de género, por lo cual se tocaban temas como la femineidad, el aborto y el movimiento homosexual, deslizando incluso críticas hacia las expresiones institucionalizadas de éste último, como el MOVILH y el MUMS (Becerra, 2011).

Este es un movimiento que rebasó las demandas por una educación gratuita y de calidad. Si hemos definido la revuelta del 2011 como un acontecimiento, es precisamente porque las prácticas que la sustentan transforman la vida cotidiana al producir ámbitos de autonomía que permiten a jóvenes y niños/as entrar en interacciones que escapan a las 
jerarquías de las cotidianidades oficiales impuestas por la familia y la escuela, particularmente a nivel de la sexualidad.

Como dimensión del acontecimiento, las tomas dan forma a una temporalidad y espacialidad contra-cultural cuya narrativa se encuentra fuera del futurismo reproductivo de la familia nuclear heteronormativa. La toma se convierte en un dispositivo o agenciamiento colectivo que produce un modo de subjetivación infanto-juvenil cuyas formas de afiliación y participación social fueron radicalmente extra-familiares. Si se entiende el deseo como un flujo constituido colectivamente dentro del campo de lo social, pero a la vez sujeto a la escisión y estratificación disciplinaria generadas por el Complejo de Edipo y la mercantilización capitalista, ¿no fue acaso el movimiento secundario una escapatoria del enclaustramiento familiar y educacional hacia un nuevo tipo de inversión social del deseo, la cual rompe con la infantilización provocada por la triangulación edípica? No se debe perder de vista el hecho que la intrusión del "afuera" que traen consigo las tomas de colegios conlleva consecuencias políticamente inesperadas: provoca precisamente un éxodo de cientos de jóvenes que los saca de sus hogares y los libera de la vigilancia y atención directa de sus padres para construir un espacio socio-cultural donde son ellos mismos los que generan sus propias normas, rompiendo con los cercos mediáticos y políticos por medio de asambleas y flujos comunicacionales que crean un territorio de recorrido propio, transversal al territorio vigilado y estratificado de la familia y el colegio. En relación a esto, un estudiante anarquista reflexiona acerca de la experiencia de la toma de la siguiente manera:

La toma sirvió también para decirle a los viejos: "no pasa nada, por mucho que me hayas prestado tu cuerpo para darme la vida, bacán gracias, pero no pasa". Cuando naces tus padres ya tenían tu vida planeada y ningún papá te dice "yo quiero que hagas lo que hice yo", no po', te dicen "quiero que seai mejor que yo". Mis padres estaban esperando que salga de cuarto y estudie en la universidad bakán, y la instancia de la toma me sirvió para conversar esas cosas y mis intereses actuales. Poderles decir: "yo no estoy de acuerdo con eso, quiero esto, si te gusta bakán, si no ahí nos vemos". Al final se tienen que dar cuenta que la vida es de uno, no te pueden tener para siempre aprisionado en la casa. (Periódico El Surco, 2012)

Papá y mamá ya no están ahí, los niños de un día para otro han dejado de ser hijos, y empiezan a brindar a todos los grandes poderes del país una gran clase de ciencia política. $Y$ no es que las figuras y funciones paternas hayan dejado de existir. Peor: adoptan una posición subordinada y residual, donde el padre y el profesor dejan de mandar y empiezan a apoyar o a obedecer el movimiento de sus hijos y estudiantes. Las tomas de colegios expresan, por lo tanto, la emergencia de una especie de temporalidad y espacialidad queer y no capitalista cuya estructuración simbólica no se ajusta a las culpas ni a las castraciones del triángulo edípico, sino que designa otra forma posible de vivir y convivir, otra forma de construir lo simbólico sin la función represora de la Ley del Padre. 
Una estudiante cuenta de la siguiente manera su experiencia como parte de esta disrupción, puntualizando los temas del género y cuerpo dentro de la ocupación y los procesos educativos autónomos relacionados con la sexualidad que allí se dieron:

En un principio la toma era súper cuadrada, era igual que estar en el colegio, horas de entrada, salida, etcétera. Al paso de los meses eso cambió, nos dimos cuenta de cosas que antes la estructura del colegio no te dejaba ver y por ejemplo decidimos no abrir las salas para no reproducir las lógicas del liceo de encerrarnos por edad y que nadie se conozca. En la toma la vida era más comunitaria, en mi colegio hasta teníamos una cama común donde dormíamos todos juntos para romper con los géneros, allí dormías con tu compañera, tu hermano, su amigo. Llegó un momento en que se hizo natural, si los locos se ponían jugosos los echábamos y listo. Se trata de romper con la sexualidad, más en nosotras que somos de un colegio de niñas y se ve súper marcado que las minas tienen mucha vergüenza de su cuerpo, el profe te trata de amachada u ordinaria por sentarte con las piernas abiertas, te dice "las señoritas tienen que estar con las piernas juntas". No se dan las instancias de conocernos nosotras mismas por eso hicimos un taller de ginecología y sexualidad, minas que no sabían donde hablarlo pudieron expresarse y conversar. (Periódico EI Surco, 2012)

La toma es el espacio y el tiempo donde los niños y jóvenes auto-gestionan colectivamente sus vidas. Los cuerpos han dejado de moverse linealmente de un espacio disciplinario a otro, han interrumpido el orden temporal y espacial del Estado y el mercado así como el mandato teleológico y futurista de la heteronormatividad, pilar sobre el cual el poder del capital descansa y se reproduce. ¿Será un atrevimiento político demasiado intolerable para algunos llamar a los jóvenes que participaron en la toma de sus colegios como sujetos y sujetas queer? ¿Por qué no? Son queer no porque la vida en las tomas estuviese necesariamente acompañada por conductas sexuales alternativas o disidentes, aunque nadie se atrevería a afirmar que nunca las hubo. Son efectivamente queer porque optaron por una vida comunitaria y corporal de varios meses que estaba completamente afuera del tiempo y espacio reproductivo de la familia y el sistema oficial de educación, y al hacerlo rompieron con la lógica de la acumulación capitalista y la heteronormatividad. Ser queer ya no se reduce sólo a las prácticas sexuales que desarticulan la matriz heterosexual. En la medida en que el modo de producción implica también el mandato de un modo de sexualidad y afectividad exclusivo, ser queer incluye la manera en que se vivencia el cuerpo en relación a un conjunto heterogéneo de relaciones sociales y libidinales por las cuales éste transita, tránsito del cual las tomas de colegios del 2011 constituyeron el mejor ejemplo. 


\section{Palabras finales}

De todas las organizaciones estudiantiles la única que demostró mayor sensibilidad política hacia las dimensiones sexuales del acontecimiento del 2011 fue la ACES. Si bien la CONES hace una breve alusión al tema de la educación sexual en su petitorio, la narrativa de la ACES al respecto va más allá, exigiendo "Implementar programas de educación sexual laica, pertinente con los requerimientos de la comunidad y con respeto a la diversidad sexual" en el marco de una educación pública bajo control comunitario (La Nación, 2011). Un año más tarde, la vocera de la organización Eloísa González se toma el tiempo para autodefinirse como lesbiana durante una conferencia de prensa, señalando que asumir públicamente su orientación sexual también corresponde a "una decisión política". Al visibilizar el cuerpo y el deseo sexual como campo estratégico de decisiones políticas, la joven activista "contribuye a pluralizar el escenario de las construcciones de sujeto ampliando los repertorios del sexo y género...despliega una fuerza performativa que repercute en multiplicar potencialidades de subjetivación político-sexual que extiende el imaginario democrático, más allá de lo controlado por una comprensión restringida de lo político que excluye el significante "cuerpo" de sus proyectos de transformación social" (Richard, 2013: 229-230). Aquí hablan cuerpos que afectan y son afectados.

El devenir de Eloísa González también es una manifestación expresiva de fuerzas afectivas que habían entrado en movimiento, de demostraciones eróticas y comunitarias que se habían desatado y multiplicado. Eloísa no hace más que resumir de manera personal un estado de cosas que la propia ACES ya había hecho colectivo, confirmando que el movimiento estudiantil secundario durante ese periodo no es tan sólo un movimiento por la educación pública sino también "la subversiva irrupción de lo no-dicho" (Richard, 2013: 216).

$\mathrm{Ni}$ el movimiento estudiantil es puramente educacional ni los estudios queer son puramente sexuales. Ambos se involucran en tráficos promiscuos de roles y posiciones somáticas que se vuelven muchas veces indistinguibles dentro de sus cursos autónomos y paralelos. Ambos han hecho de la afectividad y la exuberancia performática del cuerpo un medio de lucha. Desde el cuerpo se compone una nueva cultura colectiva, un tipo diferente de comunidad política, donde el placer sexual y la afectividad se convierten en un pilar fundamental de una verdadera vida democrática. Sin el cuerpo y sus afectos el movimiento estudiantil no se habría sostenido en el tiempo. Cualquier escritura que se produzca desde ahí es parte del juego provocado por la afectividad. La salida del cuerpo a la calle, su ocupación del territorio, su excedencia expresiva en relación al lenguaje es tan intensa que se hace imposible escribir conclusiones definitivas sin caer en la temporalidad y linealidad heteronormada que este texto ha intentado criticar desde los estudios queer. 
Los cuerpos se tuercen y son retorcidos, devoran y son devorados, marcan y se desmarcan. Si establecen una sensibilidad y sensualidad común es por medio de la circulación general de la afectividad, de la capacidad de afectar y ser afectados y producir un cuerpo político mayor a partir del encuentro de cuerpos singulares. El cuerpo en común es lo fluido y no lo sólido, la apertura y no la sutura, lo minoritario y no lo mayoritario, la multitud y no la masa. El presente texto ha buscado guardar cierta fidelidad para con ese cuerpo, para con sus desviaciones y torsiones, modelando la palabra a través de la corporalidad, persistiendo e insistiendo en ser un diagrama incompleto, situado y provisional, donde la escritura se convierte en nuestra modesta y quizá demasiada recatada manera de resistir el régimen de lo normal.

\section{BIBLIOGRAFÍA}

Adkins, Brent (2012). Deleuze and Badiou on the Nature of the Events, en Philosophy Compass, Año 7, № 8. London: Blackwell Publishing.

Aguilera, Oscar (2006). Movidas, Movilizaciones y Movimientos. Etnografía al Movimiento Estudiantil Secundario en la Quinta Región, en Revista Observatorio de Juventud, No 11. Santiago de Chile: Instituto Nacional de la Juventud.

Araujo, Kathya y Martuccelli, Danilo (2012). Desafíos comunes: retratos de la sociedad chilena y sus individuos. Santiago: Editorial LOM.

Becerra, Mauricio (2011). El exilio de las Putas Babilónicas del Liceo de Niñas en El Ciudadano. http://www.elciudadano.cl/2012/11/21/60469/el-exilio-de-las-putasbabilonicas-del-liceo-de-ninas/

Bellei, Cristián; Cabalín, Cristian y Orellana, Víctor (2014). The 2011 Chilean student movement against neoliberal educational policies" en Studies in Higher Education, Vol. 39, 2014, Nº.

Berlant, Lauren (1997). The Queen of America Goes to Washington City: Essays on Sex and Citizenship. London: Duke University Press.

Butler, Judith (1997). Excitable Speech: A Politics of the Performative. New York: Routledge.

Butler, Judith (2007). El género en disputa. El feminismo y la subversión de la identidad. Barcelona: Editorial Paidos. 
Butler, Judith (2008). Cuerpos que importan. Sobre los limites materiales y discursivos del "sexo". Barcelona: Editorial Paidos.

Córdoba, David (2005). Teoría queer: reflexiones sobre sexo, sexualidad e identidad. Hacia una politización de la sexualidad. En David Córdoba, Javier Sáez y Paco Vidarte (eds.), Teoría Queer. Políticas Bolleras, Maricas, Trans, Mestizas. Barcelona: Editorial EGALES.

Deleuze, Gilles (1988). Spinoza: Practical Philosophy. San Francisco: City Lights Books.

Deleuze, Gilles (1990). The Logic of Sense. New York: Columbia University Press.

Deleuze, Gilles (1997). Difference and Repetition. London: The Athlone Press.

Deleuze, Gilles (2010). Derrames. Entre el capitalismo y la esquizofrenia. Buenos Aires: Editorial Cactus.

Deleuze, Gilles y Guattari, Felix (1994). Anti-Oedipus: Capitalism \& Schizophrenia. Minneapolis: University of Minnesota Press.

Deleuze, Gilles y Guattari, Felix (1987). A Thousand Plateaus: Capitalism \& Schizophrenia. Minneapolis: University of Minnesota Press.

Derrida, Jacques (1973). Speech and Phenomena. Evanstone: Northwestern University Press.

Derrida, Jacques y Ferrari, Maurizio (2002). I Have Taste for the Secret. London: Polity Press.

Diprose, Rosalyn (2005). Community of Bodies: From Modification to Violence en Continuum: Journal of Media \& Cultural Studies, Año 19, № 3, London: Routledge.

Duggan, Lisa (1994). Queering the State, en Social Text, № 39. London: Duke University Press.

Edelman, Lee (2004). No Future: Queer Theory and Death Drive. London: Duke University Press.

Freud, Sigmund (1986). Los textos fundamentales de psicoanálisis. Madrid: Alianza Editorial.

Foucault, Michel (2000). Los Anormales. Buenos Aires: Fondo de Cultura Económica. 
Foucault, Michel (2012). Historia de la sexualidad. 1. La voluntad de saber. Buenos Aires: Siglo XXI Editores.

Grau, Olga (1997). Discurso, género y poder. Santiago: ARCIS / LOM.

Grau, Olga (2004). De tábulas rasas a sujeitos encarnados. En Walter Kohan, Walter (ed.), Lugares da Infancia: Filosofía. Río de Janeiro: DP\&A.

Grau, Olga (2006). Filosofía e infancia. Buenos Aires: NOVEDUC.

Grupo anarquista El Surco (2012). Un año de movimiento estudiantil secundario: críticas y aprendizajes, en El Surco. Periódico anarquista. https://periodicoelsurco.wordpress.com/2012/10/12/un-ano-de-movimientoestudiantil-secundario-criticas-y-aprendizajes-conversando-con-Ixs-pequenxssalvajes/

Guattari, Felix (2013). Líneas de fuga. Por otro mundo de posibles. Buenos Aires: Editorial Cactus.

Halberstam, Judith (2003). What's that smell? Queer temporalities and subcultural lives" en International Journal of Cultural Studies, Volume 6, № 3. London: Sage Publications.

Halberstam, Judith (2007). Forgetting Family: Queer Alternative to Oedipal Relations. En George E. Haggerty y Molly McGarry (eds.), A Companion to Lesbian, Gay, Bisexual, Transgender and Queer Studies. Oxford: Blackwell Publishing.

Halberstam, Judith (2011). The Queer Art of Failure. London: Duke University Press.

Halperin, David (1995). Saint Foucault: Towards a gay hagiography. Oxford: Oxford University Press.

Hardt, Michael y Negri, Antonio (2000). Empire. London, Harvard.

Hardt, Michael, y Negri, Antonio (2004). Multitude. War and Democracty in the Age of Empire. London: Penguin Press.

lasenza, Suzanne (2010). What is Queer about sex?: Expanding sexual frames in theory and practice" en Family Process, Volumen 49, № 3. Malden: John Wiley \& Sons. 
Jackson, Michael (2011). Conocimientos del cuerpo. En Silvia Citro (ed.), Cuerpos plurales: Antropología de y desde los cuerpos. Buenos Aires: Editorial Biblos.

Jagose, Annemarie (1998). Queer Theory. Victoria: Melbourne University Press.

Lacan, Jacques (2001). Écrits: a selection. London: Routledge.

La Nación (2011). Comunicado ACES por la toma de la Municipalidad de Santiago http://www.lanacion.cl/noticias/site/artic/20111107/pags/20111107084130.html

Mayol, Alberto (2012). No al Lucro. De la crisis del modelo a la nueva era política. Santiago de Chile: Debate.

Merleau-Ponty, Maurice (1970). Lo visible y lo invisible. Barcelona: Editorial Seix Barral.

Nancy, Jean-Luc (2000). Being Singular Plural. Standford: Standford University Press.

Negri, Antonio (1999). Insurgencies. Constituent Power and the Modern State. Minneapolis: University of Minnesota Press.

Nigianni, Chrysanthi y Storr, Merl (2009). Deleuze and Queer Theory. Edinburgh: Edinburh University Press.

Ranciere, Jacques (2009): El reparto de lo sensible. Estética y política. Santiago de Chile: Editorial LOM.

Rich, Adrianne (1996). Heterosexualidad obligatoria y existencia lesbiana". Duoda Revista d'Estudis Feministes, $\mathrm{N}^{\circ} 10$.

Richard, Nelly (2013). Crítica y Política: conversaciones con Alejandra Castillo y Miguel Valderrama. Santiago de Chile: Palinodia.

Rojas, Pablo y Méndez, Leyla (2014). Testimonio de una lucha. Las tomas secundarias en Antofagasta. Santiago de Chile: Ceibo Ediciones.

Salazar, Gabriel (2012). Movimientos Sociales en Chile: Trayectoria histórica y proyección política. Santiago: Uqbar Editores.

Sáez, Javier (2004). Teoría queer y psicoanálisis. Madrid: Editorial Síntesis.

Tironi, Eugenio (2005). El sueño chileno: comunidad, familia, y nación en el Bicentenario. Santiago de Chile: Taurus. 
Urzúa Martínez, Sergio (2015). ¿Cómo marchan los jóvenes en el Chile de la postdictadura? Algunas notas acerca de la apropiación del espacio público y el uso politico del cuerpo" en Última Década, $\mathrm{N}^{\circ} 42$.

Warner, Michael (1993). The Fear of the Queer Planet. Minneapolis: University of Minnesota Press.

Wittig, Monique (2010). El pensamiento heterosexual y otros ensayos. Barcelona: Editorial Egales. 